\title{
Thin ribs-tubular bones-dysmorphism syndrome
}

INSERM

\section{Source}

INSERM. (1999). Orphanet: an online rare disease and orphan drug data base. Thin ribstubular bones-dysmorphism syndrome. ORPHA:1506

Thin ribs-tubular bones-dysmorphism syndrome is an extremely rare, lethal, primary bone dysplasia characterized by thin ribs, thin long bones, high-arched palate and facial features of frontal bossing and low-set, posteriorly rotated ears. Bilateral cryptorchidism may be also observed. There have been no further descriptions in the literature since 1990. 